\title{
Magnetic properties of rocks from the Geitafell gabbro complex, SE Iceland
}

\author{
G. SCHOENHARTING
}

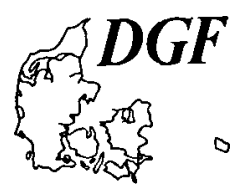

Schoenharting, G.: Magnetic properties of rocks from the Geitafell gabbro complex, SE Iceland. Bull. geol. Soc. Denmark, vol. 28, pp. 21-29, Copenhagen. October 23rd, 1979.

https://doi.org/10.37570/bgsd-1979-28-05

\begin{abstract}
The southern portion of Geitafell gabbro, SE Iceland, has been sampled in detail along a horizontal profile of $1.5 \mathrm{~km}$ length for rock magnetism analysis. Within this profile a ca. $200 \mathrm{~m}$ wide zone exists with anomalously strong NRM of reversed polarity. Magnetite enrichment in this zone - up to 5 vol\% - cannot alone account for the large NRM values. Oxidation exsolution of ilmenite in titanomagnetites and, less important, reduction exsolution of magnetite in ilmenites as well as formation of magnetite from silicates are considered the cause of the strong magnetization. During these processes at high temperatures small magnetite grains have been formed with "pseudo single domain « (psd) magnetic properties. Small stability of NRM during AF demagnetizátion rules out »single domain « grains and is interpreted as result of interaction between psd- and multi domain $\propto$ magnetic moments. The rocks studied have preserved their paleomagnetic directions since cooling. It is suggested that such rocks might contribute to marine magnetic anomalies.
\end{abstract}

Guenther Schoenharting, Institut for almen Geolagi, Øster Voldgade 10, Dk-1350 København K, Danmark, Februar I6th, 1979.

Field magnetic measurements undertaken during the summer of 1975 at Geitafell locality, Hornafjordur, SE Iceland, revealed a large negative magnetic anomaly at the southern end of the Geitafell gabbro (Schoenharting \& Petersen, in prep). This gabbro and the adjacent gabbro, dyke and sheet assemblage have been sampled along profiles $\mathrm{D}$ and $\mathrm{E}$, with a total length of about $1200 \mathrm{~m}$ (fig. 1). In all 139 sun compass oriented and 98 magnetic compass oriented drill samples (diameter $2.5 \mathrm{~cm}$, length $7 \mathrm{~cm}$ ) were taken from the gabbro, and a minimum of three samples from each of the 23 investigated dykes within the gabbro. The results from the dykes will not be dealt with here, except where intrusion of a dyke has affected the gabbro. Main emphasis is given to the investigation of the strongly magnetic zone within the southern portion of the gabbro.

Preliminary chemical analyses indicates that the magnetic zone together with some hundred metres to both sides might constitute a subunit of the gabbro. It has been intruded syngenetically by acid magma at various stages during crystallization and cooling, resulting in a variety of effects at localities E 2-E 4, D 0 and D 3, such as felsic zones with coarse-grained marginal growth rims, acid and intermediate dykes and apophyses. After cooling, but before tilting of the gabbro, basic dykes intruded the gabbro unit. The last intrusion stage was the emplacement of some basic dykes probably after the tilting phase (Schoenharting \& Petersen, in prep).

\section{Paleomagnetic measurements}

Intensities (J) and directions (I, D) of the natural remanent magnetization were measured with a P.A.R. spinner magnetometer. For this purpose the drilled samples were cut to $2.5 \mathrm{~cm}$ length. Accuracy of the NRM directions obtained for individual samples is estimated to be generally better than $3^{\circ}$. All samples were AF demagnetized in earth magnetic field compensated space using two axis tumbler device and equipment at the Geophysics Institute, Copenhagen. The NRM of 10 pilot samples from the gabbro was measured after every demagnetizing step at fields of zero, $25,50,80,120,200,300,400$, 600,1000 and 1500 Oe. It was found that directions were stable after demagnetization of a small viscous component in fields of about $50 \mathrm{Oe}$. At fields larger than 400 Oe directions occasionally began fluctuating (fig. 2). For the remaining samples a routine AF demagnetization was performed at fields of 50 and 200 Oe. Thermal demagnetization was performed on 5 pilot samples. Samples were heated in steps to $200,300,350$, 


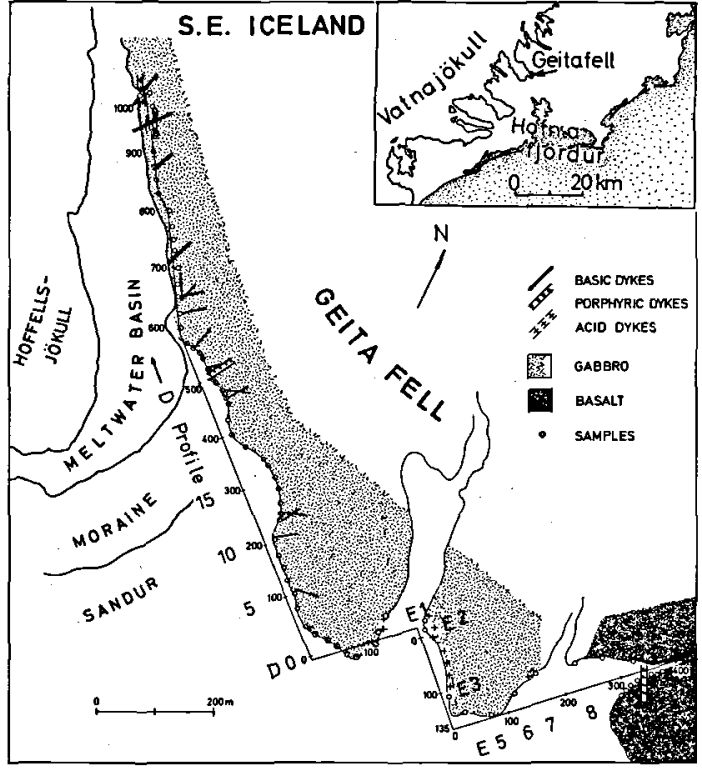

Fig. 1. Locality map of Geitafell gabbro with sample profiles D and $E$.

400,500 and $550^{\circ} \mathrm{C}$ and cooled in zero magnetic field to $20^{\circ} \mathrm{C}$ after each heating step. Directions of NRM are reasonably stable up to temperatures of $550^{\circ} \mathrm{C}$, after which generally less than $0.5 \%$ of intensity remained (fig. 2). The initial susceptibility was measured with a Kappameter, which was calibrated for the small sample size. The results of the paleomagnetic measurements are given in fig. 3. NRM intensities vary strongly in profiles $D$ and $E$. A zone of about $200 \mathrm{~m}$ width (D $0-D$ 9) exhibits large magnetizations with a maximum of $95 \times 10^{-3} \mathrm{emu} / \mathrm{cc}$ and arithmetic mean of $35 \times 10^{-3} \mathrm{emu} / \mathrm{cc}$. The remainder of the samples have a mean NRM intensity of $6 \times 10^{-3}$ emu/cc. Volume susceptibilities vary much less, from $7.3 \times 10^{-3}$ Gauss/Oe for samples from $D 0$ to $\mathrm{D} 9$ to $3.5 \times 10^{-3} \mathrm{Gauss} / \mathrm{Oe}$ for the remainder. As will be discussed later in this report, susceptibilities reflect the volume percentage of magnetite in the samples. One faces therefore the task of interpreting NRM intensity variation as other than a direct function of magnetite.

The Qn-factor, the ratio between. NRM intensity and the inductive magnetization at the site, has its largest value, about 20 , around locality DO and a logarithmic mean value of 4.5. Such values are generally taken as an indication of single domain or "pseudo-single domain « be- haviour of magnetization as an important part of the total NRM.

Values of $S_{200}$, the ratio of NRM intensity after AF demagnetization in a 200 Oe field to the original NRM, are relatively small within the zone of strong NRM intensities, averaging 0.25 . This compares to values around 0.5 outside this zone.

Corresponding »Medium Destructive Field" (MDF) values are $105 \pm 20 \mathrm{Oe}$ and $180 \pm 60 \mathrm{Oe}$ respectively.

NRM inclination and declination after $200 \mathrm{Oe}$ AF demagnetization are plotted in fig. 3. The mean values can be interpreted by remanence acquisition during a reversed earth magnetic dipole field, and a tilt of the gabbro after cooling through $35^{\circ}$ to the NW (Schoenharting \& Petersen, in prep.). A trend of steepening inclination and increasing declination from samples E 8 to D 9 has still to be explained. Deflection of remanence in the strike direction of the gabbro body caused by the gabbro's own demagnetizing field can partly explain this trend, provided cooling of the gabbro subunit proceeded from the southeast to northwest. Small NRM intensity values and

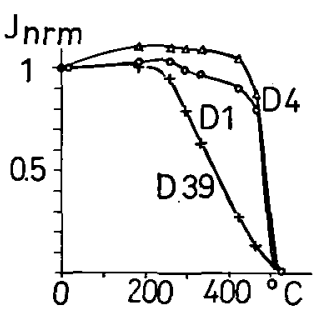

(a)

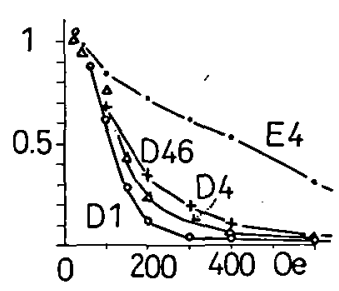

(c)

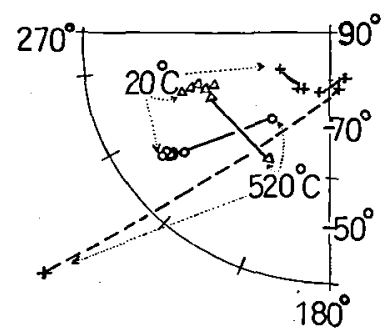

(b)

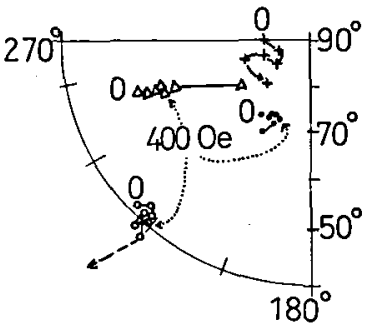

(d)
Fig.2. a) thermal demagnetization of samples D 1, D 4 and D 39. b) stereographic plot of NRM direction of samples D 1, D 4 and D 39 as function of demagnetization temperatures. c) AF demagnetization of samples E 4, D1, D 4 and D 46. d) stereographic plot of NRM directions of samples E 4, D 1, D 4 and D 46 as function of AF demagnetizing fields. 


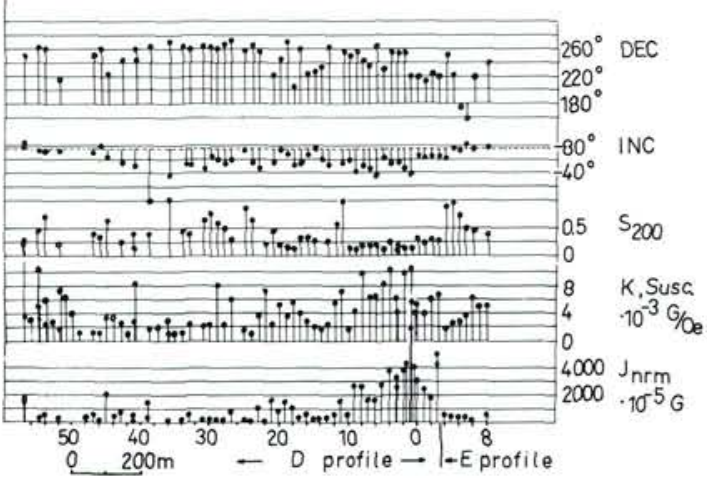

Fig. 3. Paleomagnetic parameters of gabbro samples from profiles D and E, southern portion of Geitafell gabbro.

geological field evidence for profile E 8 to D 0 indicate that later intrusions, possible sheets contemporary with the brown doleritic dykes, partially remagnetized this zone. A third possibility is a relatively fast secular variation of the earth's magnetic field during gabbro cooling, from values with westerly declinations and steep inclinations to zero declination and shallow inclination, within a time span of 500 years or so.

\section{Magnetomineralogical investigations}

\section{Methods}

Investigations comprise microscopic study of polished sections including estimation of volume percentages and grainsize of oxides, microprobe analysis on $\mathrm{Fe}$-Ti oxides and determination of the lattice constant of the cubic phase. In addition, saturation remanence has been determined and Curie points determined with the help of a thermobalance at the rock magnetism laboratories of the Universities in Bergen (Norway) and Munich (West Germany). Thermoremanence experiments have been carried out under various oxygen pressures.

\section{Microscopic study of polished sections}

Polished sections from 20 samples collected in and around the zone of strong magnetization have been inspected. The microscopic investiga-

Fig. 4. Photomicrographs $(0.5 \times 0.3 \mathrm{~mm})$ from polished sections, sample DO.4b, Geitafell gabbro, a) Crossed polars, composite titanomagnetite/ilmenite grain: Fine ilmenite trellis lamellae pattern after $\{111\}$ in the titanomagnetite. b) with magnetic colloid, same grain as a), thin magnetite rods within ilmenite, exsolution of ilmenite trellis lamellae after $\{111\}$.
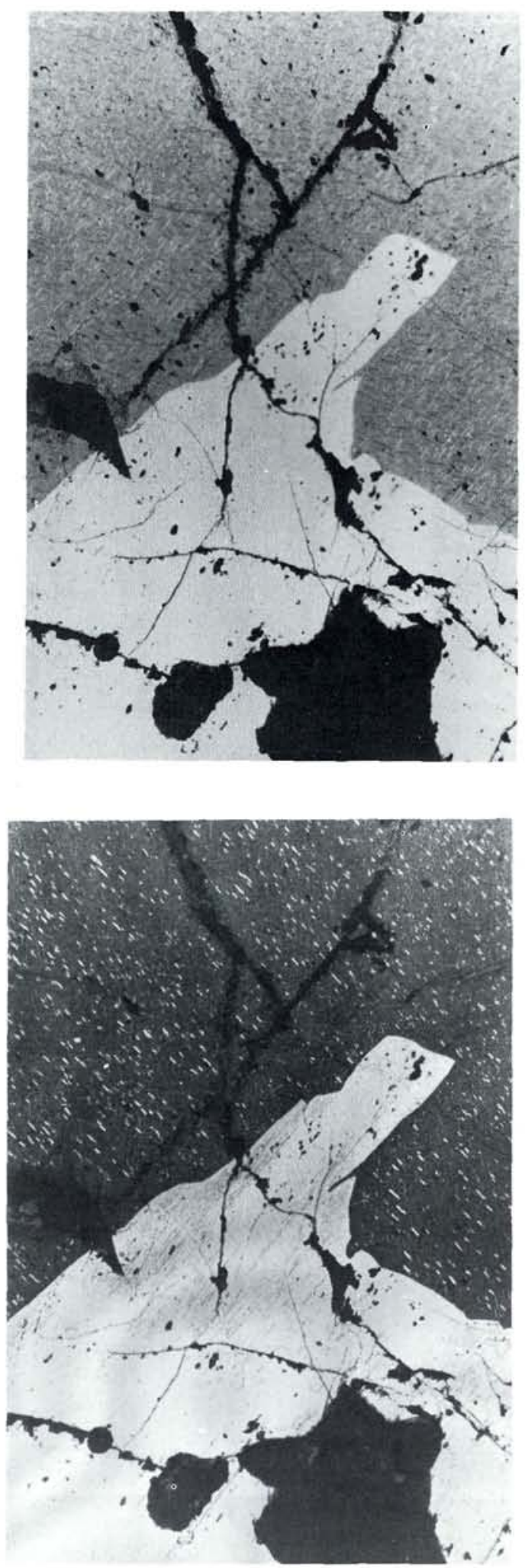

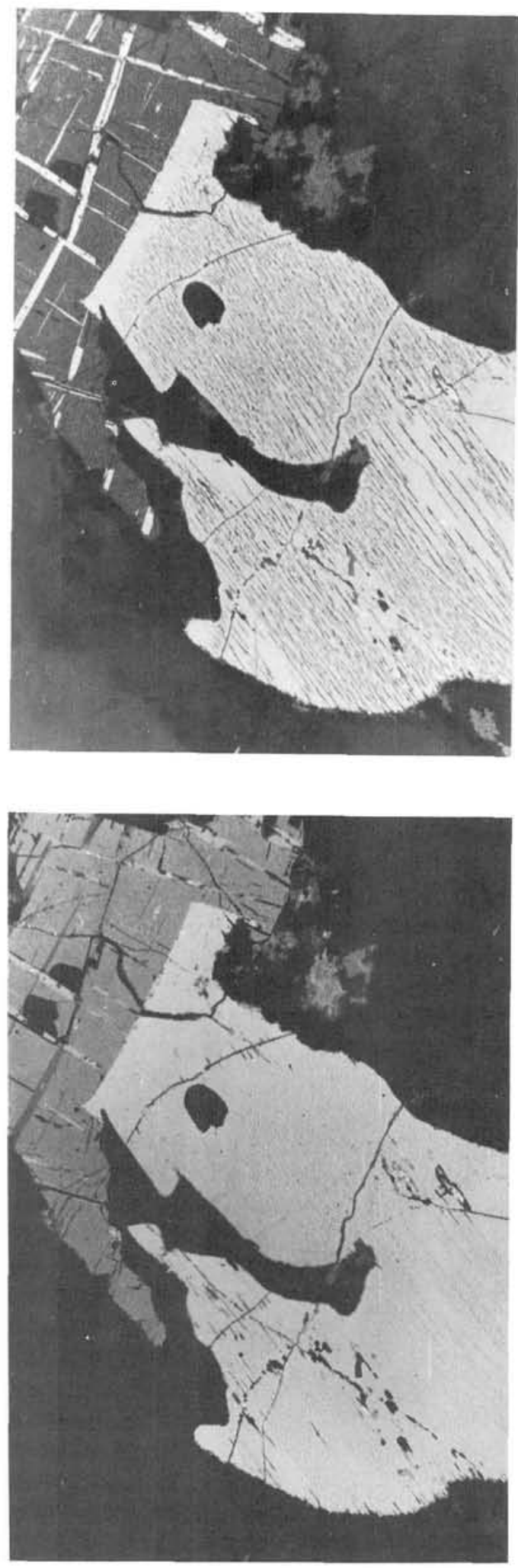

tion was supplemented by the magnetic colloid technique. Fig. 4 and fig. 5 illustrate examples of how the application of magnetic colloid enhances the optical contrast between oxide phases, if magnetic phases are present.

Main opaque minerals are ilmenite and titanomagnetite. Amount of sulfides is below 5\% of total opaque mineral content.

Ilmenite. Ilmenite is present in form of euhedral grains and in composite grains together with titanomagnetite. The composite type ilmenite can sometimes be differentiated from a "sandwich " type, the latter showing occassional signs of secondary growth. The ilmenite is rarely homogeneous and contains generally lamella type inclusions of hematite and rutile.

Samples D 0 to D 19 also exhibit a very fine pattern of magnetite lamellae within the primary ilmenite which probably is the result of subsolidus reduction exsolution of the ilmenite solid solution series. The exsolution pattern begins some $10 \mu \mathrm{m}$ from the margin of ilmenite.

Only a few examples of magnetite exsolution in ilmenite are known from literature, summarized by Haggerty (1976). For igneous rocks the only more widespread occurrences known are in trachybasalts from Teneriffa and in andesites from Peru. Jensen (1967) described ilmenite grains with magnetic lamellae found in heavy beach sand from Rågeleje, Denmark. The magnetite lamellae - like the majority of those described above - are long, straight and regularly spaced and arranged parallel to $\{0001\}$ of the ilmenite (Jensen 1967). The recognition of magnetite lamellae within ilmenite in rocks from the Geitafell gabbro was aided greatly by the use of the magnetic colloid technique, particularly where lamellar widths are close to the limit of resolution of the microscope (fig. 5).

Most of the ilmenite grains are within oxidation stages R1 and R2 (Haggerty 1976). The presence of magnetite lamellae could theoretically also be

Fig. 5. Photomicrographs $(0.5 \times 0.3 \mathrm{~mm})$ from a polished section of sample D 3 a. a) Crossed polars, composite titanomagnetite/ilmenite grain: Indication of exsolution within ilmenite, relatively thick ilmenite trellis lamellae within titanomagnetite. b) with magnetic colloid: magnetite lamellae (or rods) clearly outlined within ilmenite, magnetite zones within titanomagnetite show granulation. 
explained by hydrothermal reduction of exsolved hematite. The consequences for remanence will be discussed below.

Titanomagnetite. Primary titanomagnetite occurs mostly together with primary ilmenite in composite grains. Grain size varies between some $10 \mu \mathrm{m}$ to $500 \mu \mathrm{m}$. Almost no homogeneous titanomagnetite can be found, but exsolution patterns of different kinds exist. Ilmenite trellis lamellae exsolved parallel $\{111\}$ in the magnetite is the most common pattern. This is the result of oxidation exsolution at high temperatures from the titanomagnetite solid solution series.

Occasionally, exsolution after $\{100\}$ can be recognized; the ilmenite in this case is probably derived from oxidation of ulvöspinel, the latter being formed below $600-700^{\circ} \mathrm{C}$ from the titanomagnetite. The thickness of ilmenite trellis lamellae varies generally between 1 and $5 \mu \mathrm{m}$; these lamellae completely separate magnetite-enriched areas often below $10 \times 2 \mu \mathrm{m}$ in size. Where the enclosed magnetite areas become larger, zones of inhomogenity appear within the magnetite in form of a "granulation ". This effect is most pronounced in the vicinity of cracks penetrating the magnetite grains. The granulation pattern is interpreted as resulting from hydrothermal alteration and the "granules « of about 0.5 to $2 \mu \mathrm{m}$ size represent possibly centres of hematite growth. If this is correct, then reduction of hematite lamellae to magnetite within the primary ilmenite during the hydrothermal stage cannot have taken place.

No distinct maghemite has been noted under the microscope. Thermomagnetic measurements, however, indicate that a minor amount exists, at the most ca 5 to $10 \%$ of the magnetite content. Thermal demagnetization of NRM shows clearly that maghemite is not an important carrier of remanence in the gabbro samples (sample D 39 is probably an exception).

The titanomagnetite most often belongs to oxidation stage C2 and C3 (Haggerty 1976) with minor proportions of stage $\mathrm{C} 4$ and rarely $\mathrm{C} 1$.

The magnetite contains about $5 \% \mathrm{Fe}_{2} \mathrm{TiO}_{4}$ and ca $2 \% \quad \mathrm{Al}_{2} \mathrm{O}_{3}$ in solid solution (microprobe analyses).

Almost pure magnetite is also present; this formed as a secondary mineral on the rims of the alterated silicates (pyroxenes and/or olivines, fig.

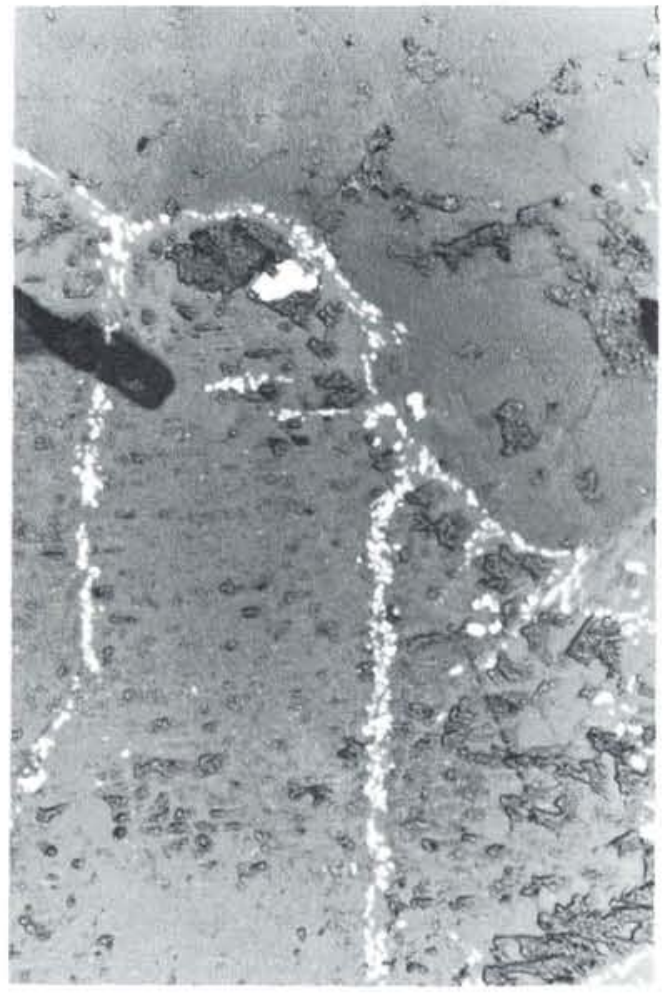

Fig. 6. Photomicrograph $(0.5 \times 0.3 \mathrm{~mm})$ from a polished section of sample E4a: Secondary magnetite, formed at the rims of altered silicates.

6). This magnetite is optically homogeneous. Grain size varies between ca $10 \mu \mathrm{m}$ down to submicroscopic size. Volume percentage is estimated to be below $10 \%$ od the total magnetite content.

Modal percentages of primary ilmenite and titanomagnetite have been determined from the polished sections as $2.2 \% \pm 1 \%, 3 \% \pm 1.5 \%$ respectively.

Estimation of the original composition of primary titanomagnetite was derived from the ilmenite/magnetite proportion of single titanomagnetites and of composite grains. In the latter case, ilmenite with magnetite exsolution pattern has not been included in the calculation. A result of $65 \%$ ulvöspinel $-35 \%$ magnetite has been obtained on the average.

Saturation magnetizations determined with the thermobalance and using the measured magnetite composition can be used to determine the magnetite content of the samples and to calibrate the relationship between measured suscep- 


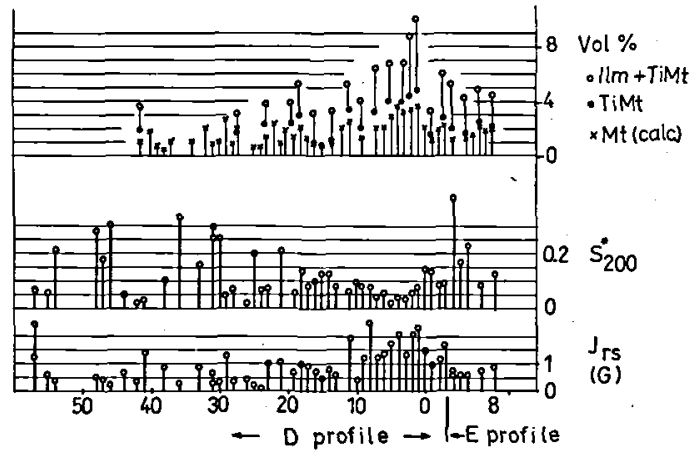

Fig. 7. Some magnetomineralogical parameters of Geitafell gabbro samples: (from the bottom to top) saturation remanence $J_{r s}$ in Gauss (emu/cc), stability $S_{200}$ of $J_{r s}$ optically determined primary ilmenite + titanomagnetite (open circles), primary titanomagnetite content (full circles) and magnetically determined magnetite content (crosses).

tibilities with regard to magnetite content. A value of $450 \mathrm{emu} / \mathrm{cc}$ for the magnetite has been used for this purpose. The magnetically and optically determined magnetite contents are in good agreement if allowance for ilmenite lamellae is made (fig. 7). Magnetite content is larger by a factor of 4 within the zone of strong magnetization $\left(D_{0}-D_{9}\right)$ compared to the remainder of the profile.

Curie temperature and the lattice constant.

Curie temperatures have been determined by means of a thermobalance in fields of $2000 \mathrm{Oe}$. Curie points vary between $535^{\circ}$ and $555^{\circ} \mathrm{C}$ for samples $E 6$ to $D 19$. Some trend is indicated with the higher values towards the southeastern boundary of the gabbro. Correcting for the influence of Al (Pickart \& Turncock 1959, Richards, O'Donovan, Hauptmann, O'Reilly \& Creer 1973) and using the measured lattice constant of $8.40 \AA$ (sample D 3) an almost stoichiometric titanomagnetite with ca 5\% ulvöspinel was found with the help of the Readman \& O'Reilly (1972) diagram.

\section{Thermoremanence experiments.}

Representative samples from profiles $D$ and $E$ have been heated above the Curie points of magnetite and thereafter cooled in the magnetic field of the laboratory $(0.4 \mathrm{Oe})$. Heating was performed in two different oxygenic atmospheres. The $\mathrm{O}_{2}$ pressure in the oven was established by means of a gas mixing technique, using
$\mathrm{N}_{2}, \mathrm{H}_{2}$ and $\mathrm{CO}_{2}$ in varying proportions (Larson, Hoblitt \& Watson 1975) that should correspond to the varying stability oxygen fugacities of the magnetite in the sample during heating (Buddington and Lindsley, 1964). The control of the gas flow was performed with flow meters. Oxygen pressures established with help of flow control can be wrong by a factor of 10 or even 100 (Larson, Hoblitt \& Watson 1975). For temperatures below $200^{\circ}$ to $300^{\circ} \mathrm{C}$, during heating experiment, no oxidation is likely to result from inaccurate oxygen pressures. Also at temperatures between $300^{\circ}$ and $600^{\circ} \mathrm{C}$ phase changes of magnetite are considered unlikely to be of importance in view of the short duration ( $30 \mathrm{~min}$.) of the experiment in this critical interval.

After heating to $600^{\circ} \mathrm{C}$ the samples were taken out of the oven and cooled rapidly in cold water. Cooling time from $600^{\circ}$ to $100^{\circ} \mathrm{C}$ was about 1 $\min$. The acquired thermoremanence $\left(\operatorname{TRM}_{(\mathrm{a})}\right)$ in the 0.4 Oe field is shown in fig. 8. The curve looks much like the distribution of NRM. Values are about $20 \%$ lower than NRM. This can be interpreted by a NRM of thermoremanent origin, acquired in a $25 \%$ stronger earth field, i.e. 0.5 Oe.

It can also be argued that the $20 \%$ lower values are not significant, in view of the inhomogeneity of the samples. Stability values $S_{200}$ are very similar for NRM anf $\operatorname{TRM}_{(a)}$ and support the same mode of origin.

A test has also been carried out by heating samples in air to $600^{\circ} \mathrm{C}$ and then cooling them down as described above. The resulting $\operatorname{TRM}_{(\mathrm{b})}$ does not correlate closely with the NRM curve. Stability values $S_{200}$ are scattered widely, but are

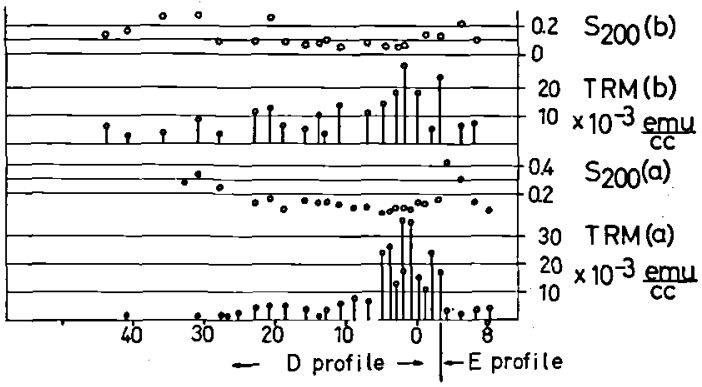

Fig. 8. TRM (thermoremanence) of Geitafell gabbro samples. TRM(a) was produced by heating samples at $\mathrm{O}_{2}$ pressures of about $10^{-15}$ atm and fast cooling in air in 0.4 Oe field. TRM(b) was produced by heating in air and cooling down as for TRM(a). $S_{200}$ values are the corresponding stabilities in ac fields. 
generally higher than $\operatorname{TRM}_{(a)}$. It is likely that martitisation of the titanomagnetite ground mass caused development of single domain magnetite centres with increased $\mathbf{S}_{\mathbf{2 0 0}}$ stability.

Saturation remanence $\left(J_{\mathrm{sr}}\right)$ measurements. $\mathrm{J}_{\mathrm{sr}}$ has been achieved in fields up to $10 \mathrm{kOe}$. Values are shown in fig. 7. The curve can be correlated roughly with magnetite content and with the susceptibility curve. After demagnetization in $200 \mathrm{Oe} A F$ field, no relative increase of $\mathrm{J}_{\mathrm{sr}}$ intensities occurs over the zone D 0 to D 9. The relationship of $\mathbf{J}_{\mathbf{s r}}$ to saturation magnetization varies between 0.07 and 0.15 , reflecting low bulk-coercivities of 40 to 80 Oe (Nagata, 1961).

\section{Discussion and Conclusions}

To explain the large variation of NRM across the gabbro profiles $D$ and $E$, two seemingly contradicting pieces of evidence have to be discussed. Firstly, the variation of magnetite content explains less than half of the NRM intensity variation. Secondly, the large NRM intensities are coupled with low stability values $S_{200}$ in AF demagnetizing fields.

Multidomain remanence theory gives a linear relationship between magnetite content and TRM. It could explain the low $S_{200}$ values between D 0 and D 9 samples, assuming that the magnetite increase in this zone corresponds to an increase in multidomain grains (perhaps by increase of grain size). Multidomain theory can, however, not at all account for the observed large NRM intensities, but for only $10 \%$ of these, assuming thermoremanent origin.

Single domain theory, on the other hand, easily can account for observed NRM intensities, provided appropriate small "effective grain size « is present. This latter condition is often difficult to observe as submicroscopic particles might substantially contribute to NRM. However, stability values should be much higher than found. The Medium Destructive Field (MDF) compares directly to the coersivity of remanence. For the measured samples MDF values are by a factor of at least 5 too low if single domains are assumed.

It has been argued that so called »pseudo single domain « (psd) particles can give considerable NRM intensities, provided sufficiently small effective grain sizes are present (e.g. Stacey \& Bannerjee 1974, Dickson, Everitt, Parry \& Stacey 1966). Psd behaviour can arise from various effects as the magnetization of domain walls or the magnetostatic effects of nonmagnetic inclusions. More often psd effects arise from irregularities at the surface of multidomain grains. Stabilities depend on the magnetostatic fields between multidomain and psd areas as well as on magnetostrictive and shape/crystal anisotropy values.

Formulae are given to describe TRM intensity versus psd grain size (Stacey \& Bannerjee 1974). It follows, that the observed NRM could arise from $3 \%$ of the determined magnetite content in the samples, provided the psd size is below $1 \mu \mathrm{m}$.

As candidates for the carriers of NRM, psd type, three different magnetite types have to be discussed:

Magnetite lamellae within ilmenite

Magnestostatic effects between adjacent magnetite lamellae at temperatures between $555^{\circ}$ and $500^{\circ} \mathrm{C}$ (Curie- and blocking temperatures) prohibit parallel alignment of magnetic moments in fields of the order $1 \mathrm{Oe}$. Only if lamellae thicknesses are below $0.01 \mu \mathrm{m}$ does the magnetostatic interaction become less dominant and parallel alignment can result to some degree. Microscopic observations indicate lamellae thicknesses to be generally between 0.1 and 1 $\mu \mathrm{m}$. If smaller sizes are also present - which is possible as the magnetic colloid technique enlarges the observable magnetite surface - then the resulting NRM is too small by a factor of 5 .

Another effect of psd type is also considered here, assuming a chain like magnetic moment configuration, shown in fig. 9. At the ends of magnetite lamellae, earth magnetic field and magnetostatic interaction might combine to disturb the antiparallel alignment of neighbouring lamellae. Such an effect is estimated to result in a NRM intensity comparable to that of the single domains mentioned above.

Magnetite within titanomagnetite.

Several possibilities of psd structures exist here because of the different exsolution patterns found. Exsolution has resulted in a large increase of the surface area of the magnetite with cor- 


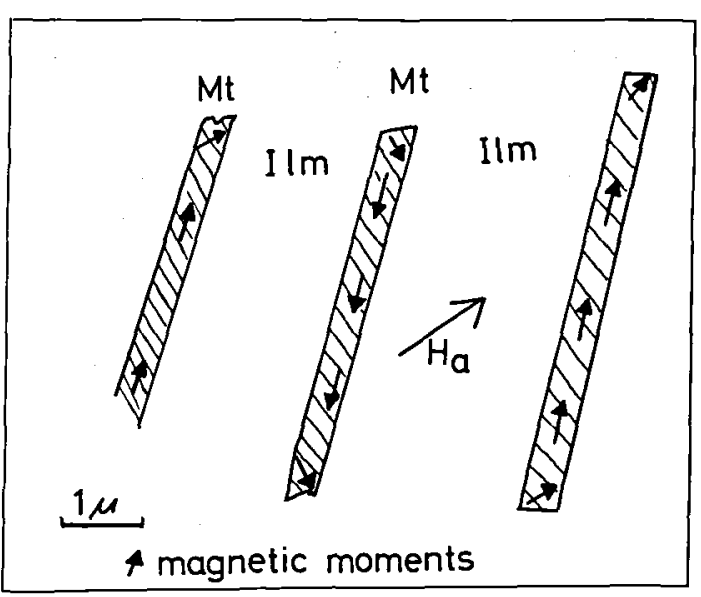

Fig. 9. Pseudo single domain effects at the ends of magnetite lamellae within ilmenite: Magnetostatic interaction between adjacent lamellae in earth magnetic field $\mathrm{H}_{\mathbf{a}}$ can result in thermoremanent psd moments.

responding increase of potential psd areas. Magnetostatic effects between adjacent psd moments will exist, but become smaller with increasing ilmenite lamellae thickness, and psd moments will increasingly contribute to NRM. One might also speculate as to what degree the "granulation « structure of the larger magnetite areas can in fact exhibit psd behaviour. Remanence type would be a CRM as a result of oxidation below the magnetite Curie point. Samples with the magnetite granulation pattern described tend to have smaller NRM intensities and are here not considered further for solving the problem of large NRM values.

Secondary magnetite from silicates.

This magnetite appears optically homogeneous and is therefore thought not to contribute particularly to NRM for grain sizes larger than $1 \mu \mathrm{m}$. Conversely, for the possible existing single domain grain sizes, stability values do not fit.

In conclusion, magnetite areas within primary titanomagnetite are the most promising candidates for psd behaviour. An explanation has then to be found for the low stability values $S_{200}$ of the supposed psd moments. The direct neighbourhood of multidomain areas is probably of importance. Demagnetization of the unstable and weak multidomain NRM occurs already in low ac-fields of some 50 Oe or so. The "effective" demagnetizing ac-field at the psd location then increases by an inductive component from the multidomain neighbour, provided psd and multidomain grains are aligned parallel to the external field.

As all psd moments will come into such a position during rotation of the sample, the apparent stability of psd remanence becomes considerably smaller. For example, an induced magnetization of multidomain magnetite-cylinders in an ac-field of 150 Oe may result in a magnetic field of 300 Oe at the psd location. It is not possible to locate the psd moments by magnetic or optical methods. Thus at present this more qualitative explanation will have to suffice.

The high temperature oxidation exsolution of the titanomagnetite apparently has not proceeded so far as to completely isolate single domain size magnetite. By this process, even larger mean magnetization intensities with greater $S_{200}$ stabilities could possibly have resulted (see e.g. McClay 1974, Wilson, Haggerty \& Watkins 1968, Watkins \& Haggerty 1967).

On the basis of the 20 polished sections investigated, significant variation in the exsolution pattern in the titanomagnetite has not been positively identified, although some increase in density of fine trellis type ilmenite pattern is possibly present in titanomagnetite from the strongly magnetized zone. This will be further examined in the near future.

In conclusion, large NRM intensities of portions of the Geitafell gabbro arise from only $3 \%$ or less of the total magnetite contained in the sample. The susceptibility and saturation magnetization is proportional to the total magnetite content, whereas the NRM intensity, being of the thermoremanent origin, shows psd behaviour. NRM is dependent on the geometry and degree of ilmenite exsolution within magnetite which creates new internal magnetite surfaces and increases thereby psd effects. Psd effects in magnetite lamellae within ilmenite grains possibly also contribute to a minor degree to the total NRM.

The question arises if the relatively low stability values $S_{200}$ encountered are an indication that the rocks sampled are not suitable for recording the intensity and direction of the earth's magnetic field throughout geological time. Thermal demagnetization experiments have shown $\mathrm{NRM}$ intensity to be stable up to $500^{\circ} \mathrm{C}$ under laboratory conditions. Blocking temperatures of over $500^{\circ} \mathrm{C}$ are an indication that thermal relaxa- 
tion during geological time may be of only minor importance. The age of the gabbro may be inferred from $\mathrm{K} / \mathrm{Ar}$ measurements on intrusions in the region to be within the range $2-6 \times 10^{6}$ years. The strong reversed NRM intensity was obviously stable enough to withstand the alternating earth magnetic field.

It is concluded that the gabbro samples are suitable material for paleomagnetic purposes. If such rocks can be assumed to occur fairly widespread in the lower portion of oceanic layer 2 (and perhaps also in layer 3) then their contribution to marine magnetic anomalies has to be considered besides contributions from pillow basalts and dyke swarms.

Acknowledgements. K. Strand Petersen and S. Lauge Petersen helped the author during the field trip. A number of scientists from various institutes assisted during laboratory measurements:

P. V. Sharma, Copenhagen, N. Abrahamsen, Arhus, R. Lovlie, Bergen and N. Petersen, Munich are thanked for helpful discussions and making laboratory facilities available. E. Leonardsen determined the lattice constants of magnetite/ilmenite and J. Rønsbo carried out the microprobe analysis. Anne-Lise Jensen helped with laboratory measurements while T. C. R. Pulvertaft and Aa. Jensen improved the language of the manuscript. The Danish Natural Science Research Council supported the work under grants J.Nr. 511-6633 and J.Nr. 511-10147 and the Icelandic Research Counsil granted permission for the field trip to South-East Iceland.

\section{Dansk sammendrag}

Langs et $1,5 \mathrm{~km}$ langt horisontalt tværprofil $\mathbf{i}$ den sydlige Geitafell gabbro, $S \emptyset$ Island, er der foretaget en undersogelse af de magnetiske egenskaber og tilknyttede mineralkomponenter. Et ca. $200 \mathrm{~m}$ bredt område i gabbroen med usædvanlig stor remanent magnetisering og invers polaritet er analyseret. En relativ forogelse af magnetitinholdet - op til 5 vol. \% - kan kun delvis forklare de store magnetiseringsvardier. Oxidations-afblandings lameller af ilmenit udfra titanomagnetit og reduktions-afblandning af magnetit fra ilmenit sammen med sekundær magnetit dannet fra silikater betragtes som årsag til den store remanente magnetisering, fordi der opstod små »effektive magnetiske korn med «pseudo single domain (psd) mag- netisk egenskab. Relativ lille stabilitet overfor vekselfeltafmagnetiseringen er fortolket som en vekselvirkning imellem psd- og »multidomain « korn. Bjergartsprøverne er velegnede til palæomagnetiske bestemmelser. Hvis materialet er udbredt $\mathbf{i}$ den dybere del af det oceane lag 2 og/eller lag 3 kan det bidrage betydningsfuldt til dannelsen af magnetiske anomalier.

\section{References}

Buddington, A. F. and Lindsley, D. H. 1964: Iron titaniumoxide minerals and synthetic equivalents. $J$. Petrol. 5: 318.

Dickson, G. O., Everitt, C. W. F., Parry, L. G. and Stacey, F. D. 1966: Origin of thermoremanent magnetization. Earth Planet. Sci. Lett. 1, p. 222.

Haggerty, S. E. 1976: Opaque mineral oxides in terrestrial igneous rocks, in: Oxide Minerals, ed. by D. Rumble, III, Mineral. Soc. Am. Short Course Notes, Nov. 1976.

Jensen, Aa. 1976: Opaque minerals in the heavy beach sand from Rågeleje, Denmark. Meddr Dansk Geol. Foren. 17:21-36.

Larson, E. E., Hoblitt, R. P. and Watson, D. E. 1975: Gas-mixing techniques in thermomagnetic analysis. Geophys. J. R. astr. Soc. 43, p. 607.

McClay, K. R. 1974: Single-domain magnetite in the Jimberlana norite, Western Australia. Earh Planet. Sci. Lett. 21: 367-376.

Nagata, T. 1961: Rock Magnetism. Maruzen Co. Ltd., Tokyo, p. 137.

Prickart, S. J. and Turncock, A. C. 1959: Magnetic properties of solid solutions of $\mathrm{Fe}_{3} \mathrm{O}_{4}$ and $\mathrm{FeAl}_{2} \mathrm{O}_{4}$. J. Phys. Chem. of solids. 10: 242-244.

Readman, P. W. and O'Reilly, W. 1972: Magnetic properties of oxidized (cation deficient) titanomagnetites. J. Geomagn. Geoelectr. 24: 69-90.

Richards, J. C. W., O'Donovan, J. B., Hauptman, Z., O'Reilly, W. and Creer, K. M. 1973: A magnetic study of titanomagnetite substituted by magnesium and aluminium. Phys. Earth \& Planet. Inter. 7: 437-444.

Schoenharting, G. and Strand Petersen, $K$. in prep.: The Hvannadalur and Geitafell intrusions, SE Iceland: magnetic anomalies, structure and the magnetic layer problem.

Stacey, R. D. and Bannerjee, S. K. 1974: The physical principles of rock magnetism. Elsevier Publ. Co.: 105-145.

Watkins, N. D. and Haggerty, S. E. 1967: Primary oxidation variation and petrogenesis in a single lava. Contrib. Mineral. Petrol. 15: 251-271.

Wilson, R. L., Haggerty, S. E. and Watkins, N. D. 1968: Varitation of palaeomagnetic stability and other parameters in a vertical traverse of a single Icelandic Lava. Geophys. J. R. Astr. Soc. 16: 79-95. 